\title{
Stainless steel structures - research, codification and practice
}

\author{
L. Gardner \& F. Walport \\ Imperial College London, London, UK
}

\begin{abstract}
This paper provides a summary of recent developments in research, codification and design practice surrounding the structural use of stainless steel, with an emphasis on structural stability. Stainless steel has a nonlinear material response and this directly influences the structural behaviour. Guidance on material nonlinearities in international design standards largely relates to the occurrence of traditional idealised plastic hinges, as seen in carbon steel structures. However, such hinges do not form in stainless steel structures. Design codes provide the design framework that structural engineers use to demonstrate structural safety. With stainless steel being a high value material, its efficient use is paramount, and this is a particular incentive to embrace the opportunities offered by advanced system-level analysis and design. The most accurate representation of the behaviour of a structure is achieved by directly allowing for instability, plasticity, residual stresses and initial geometric imperfections in a second order inelastic analysis. This paper presents an overview of recent developments in the stability design of stainless steel structures, due to be included in upcoming revisions of prEN 1993-1-4, AISC 370 and ASCE-8; inclusion of these new provisions for advanced analysis in these codes represents a huge opportunity for enabling more widespread application of stainless steel in structural applications. Recent applications of stainless steel in practice are also presented herein and, with a view to the future, opportunities for the application of advanced design and construction methods to stainless steel structures are explored.
\end{abstract}

\section{INTRODUCTION}

Stainless steel is a high-performance construction material that is synonymous with modern, resilient and sustainable construction. There is a wide variety of grades to suit a range of applications and demands. The initial cost of stainless steel is relatively high compared to carbon steel (typically 3-5 times); it is therefore particularly important that design codes make efficient use of the material properties based on a comprehensive understanding of the structural response and embrace advanced design methods that may deviate from traditional approaches. Increased availability and sophistication of advanced computational tools is transforming the landscape of structural design. Advanced analysis allows for more efficient, more accurate and safer design as well as the potential for more optimised design solutions.

Stainless steel has a nonlinear material response and this directly influences the structural behaviour. It is important that this is reflected in design methodologies to enable the safe and efficient assessment and design of stainless steel structures. Design codes provide the design framework that structural engineers use to demonstrate structural safety. As structural systems become more complex, the shortcomings of the current design standards become more marked, requiring an increased level of idealisation and design assumptions. Eurocode 3 is currently under revision and a new version of each part, including EN 1993-1-4 (prEN 1993$1-4,2020)$ for the design of stainless steel structures, is due for publication in about 2023. Work is also currently ongoing on the preparation of the first American design standard for 
hot-rolled and welded stainless steel construction, AISC 370 (AISC, 2020). These codes closely mirror their carbon steel counterparts (AISC, 2016; prEN 1993-1-1, 2020), but deviate where necessary to account for the differences in material behaviour between stainless steel and carbon steel and the resulting influence on structural behaviour (SCI, 2020; Baddoo \& Francis, 2014; SCI, 2017). Additionally, new codified provisions for the design of steel and stainless steel structures by finite element (FE) analysis are in preparation for the upcoming prEN 1993-1-14 (prEN 1993-1-14, 2019); this will include detailed rules for FE analysis, material models, including a two-stage Ramberg-Osgood material model (Arrayago, Real \& Gardner, 2015) for stainless steel and cold-formed steel (Gardner \& Yun, 2018), equivalent bow imperfections for inelastic analysis (Walport, Gardner \& Nethercot, 2020b) and CSM strain limits, enabling design by second order inelastic analysis to be carried out. The current absence of appropriate guidance on system-based design is a barrier to the optimal use of stainless steel in construction. These new international design provisions will enable the more accurate and sophisticated design of stainless steel structures, promoting their wider use in practice.

In this paper, the material stress-strain response of stainless steel is first discussed as this is fundamental to developing an understanding of the structural response at the cross-section, member and frame levels. With an emphasis on frame level design, Sections 3 and 4 provide an overview of the key developments introduced above for the stability design of stainless steel structures in prEN 1993-1-4 and AISC 370, respectively. In Section 5, recent applications of stainless steel in practice are presented and, with a view to the future, opportunities for the application of advanced design and construction methods to stainless steel structures are explored. Finally conclusions are drawn in Section 6.

\section{MATERIAL NONLINEARITY}

An accurate description of the material behaviour is crucial for the reliable assessment of a structural system. If material nonlinearity is considered in the global analysis of a frame, greater deflections ensue due to the loss of material stiffness (Walport et al., 2019; Walport, Gardner \& Nethercot, 2019; Gardner, 2019) and, neglecting the effects of material nonlinearity can result in over-predictions of system strength (Walport, Gardner \& Nethercot, 2020b).

Stainless steel differs significantly from carbon steel in that its stress-strain curve is characterised by a rounded response with no sharply defined yield point. A number of material models have been developed to describe this nonlinear stress-strain behaviour, with the most widely used based on the basic Ramberg-Osgood formulation, as modified by Hill (Ramberg \& Osgood, 1943; Hill, 1944). While this formulation provides an accurate representation for the degree of nonlinearity in certain regions of the stress-strain curve, depending on the choice of the strain hardening exponent, it does not, in general, provide an accurate representation of the full curve. This has led to the development of some two-stage Ramberg-Osgood models, notably by (Mirambell \& Real, 2000; Rasmussen, 2003; Gardner \& Nethercot, 2004; Gardner \& Ashraf, 2006; Arrayago, Real \& Gardner, 2015).

The modified Ramberg-Osgood model, given in Equations (1) and (2), where $\varepsilon$ and $\sigma$ are the strain and stress respectively, $f_{\mathrm{y}}$ is the yield $(0.2 \%$ proof $)$ stress, $E$ is the Young's modulus, $f_{\mathrm{u}}$ is the ultimate stress, $E_{\mathrm{y}}$ is the tangent modulus at the yield $(0.2 \%$ proof $)$ stress, defined by Equation (3), $\varepsilon_{\mathrm{u}}$ is the ultimate strain, and $n$ and $m$ are the strain hardening exponents, is currently provided in EN 1993-1-4 (EN 1993-1-4:2006 + A1:, 2015) and the Fourth Edition of the Design Manual for Structural Stainless Steel (SCI, 2017).

$$
\begin{gathered}
\varepsilon=\frac{\sigma}{E}+0.002\left(\frac{\sigma}{f_{y}}\right)^{n} \text { for } \sigma \leq f_{y} \\
\varepsilon=0.002+\frac{f_{y}}{E}+\frac{\sigma-f_{y}}{E_{y}}+\varepsilon_{u}\left(\frac{\sigma-f_{y}}{f_{u}-f_{y}}\right)^{m} \text { for } f_{y}<\sigma \leq f_{u}
\end{gathered}
$$




$$
E_{y}=\frac{E}{1+0.002 n \frac{E}{f_{y}}}
$$

An alternative form of the second stage is given by Equation (4), where $\varepsilon_{0.2}$ is the total strain at the $0.2 \%$ proof stress, equal to $0.002+f_{\mathrm{y}} / E$, which provides increased accuracy in the region of the ultimate stress, particularly for less ductile materials e.g. ferritic stainless steels; this is the model due to be included in the upcoming prEN 1993-1-14 (prEN 1993-1-14, 2019).

$$
\varepsilon=\varepsilon_{0.2}+\frac{\sigma-f_{y}}{E_{y}}+\left(\varepsilon_{u}-\varepsilon_{0.2}-\frac{f_{u}-f_{y}}{E_{y}}\right)\left(\frac{\sigma-f_{y}}{f_{u}-f_{y}}\right)^{m} \quad \text { for } \quad f_{y}<\sigma \leq f_{u}
$$

The two-stage Ramberg-Osgood expression has also been applied to the modelling of stainless steel material behaviour at elevated temperature (Gardner et al., 2010), where the second strain hardening exponent $m$ (denoted $m_{\theta}$ at elevated temperature) can be defined explicitly with reference to the strength at $2 \%$ strain $\sigma_{2, \theta}$, the value of which is provided in structural fire design standards including EN 1993-1-2 (EN 1993-1-2, 2005). The elevated temperature stressstrain curve is forced to pass through $\sigma_{2, \theta}$ at $2 \%$ strain by defining $m$ in the following manner (Liang et al., 2019), where symbols are as previously defined with $\theta$ denoting elevated temperature:

$$
m_{\theta}=\frac{\ln \left(\frac{\varepsilon_{u, \theta}}{0.02-\varepsilon_{0.2, \theta}-\frac{\sigma_{2, \theta^{-}} \sigma_{0,2, \theta}}{E_{0.2, \theta}}}\right)}{\ln \left(\frac{\sigma_{u, \theta}-\sigma_{0.2, \theta}}{\sigma_{2, \theta}-\sigma_{0.2, \theta}}\right)}
$$

\section{STABILITY DESIGN OF STAINLESS STEEL STRUCTURES IN EUROCODE 3}

EN 1993-1-4 gives supplementary guidance for the design of stainless steel structures that complements the design rules given for carbon steel in EN 1993-1-1. The supplementary rules for stainless steel currently give no additional information for the global analysis of stainless steel structures. The guidance on material nonlinearities in EN 1993-1-1 largely relates to the occurrence of traditional idealised plastic hinges, as seen in carbon steel structures. However, such hinges do not form in stainless steel structures; instead zones of plasticity with gradually reducing stiffness, but often with peak capacities well in excess of the traditional plastic moment are exhibited (Theofanous et al., 2014). Eurocode 3 is currently under revision; this section summarises the key changes to the codified provisions for the stability design of stainless steel structures due to be included in prEN 1993-1-4 (prEN 1993-1-4, 2020).

\subsection{Material nonlinearity at frame level}

Degradation of stiffness significantly affects the behaviour of a structural system and consequently, the distribution of internal forces and moments (Walport, Gardner \& Nethercot, 2019). Figure 1 shows the ratio of moments from first order and second order plastic zone analyses using the two-stage Ramberg Osgood material model of an austenitic stainless steel portal frame plotted against the ratio of the secant modulus $E_{\mathrm{s}}$ to elastic modulus $E$ of the most heavily stressed point of the frame for increasing load levels (Walport et al., 2021). Depending on the location in the frame, ignoring material nonlinearity can result in both over-estimations and under-estimations of internal forces and moments. When the ratio of $E_{\mathrm{s}} / E$ is less than 0.2 , these errors approach $10 \%$; therefore, Equation 6 , where $E_{\mathrm{s}}$ is the secant modulus as calculated using Equation 7, is proposed to define the limit beyond which members in the frame are deemed to remain predominantly elastic. 


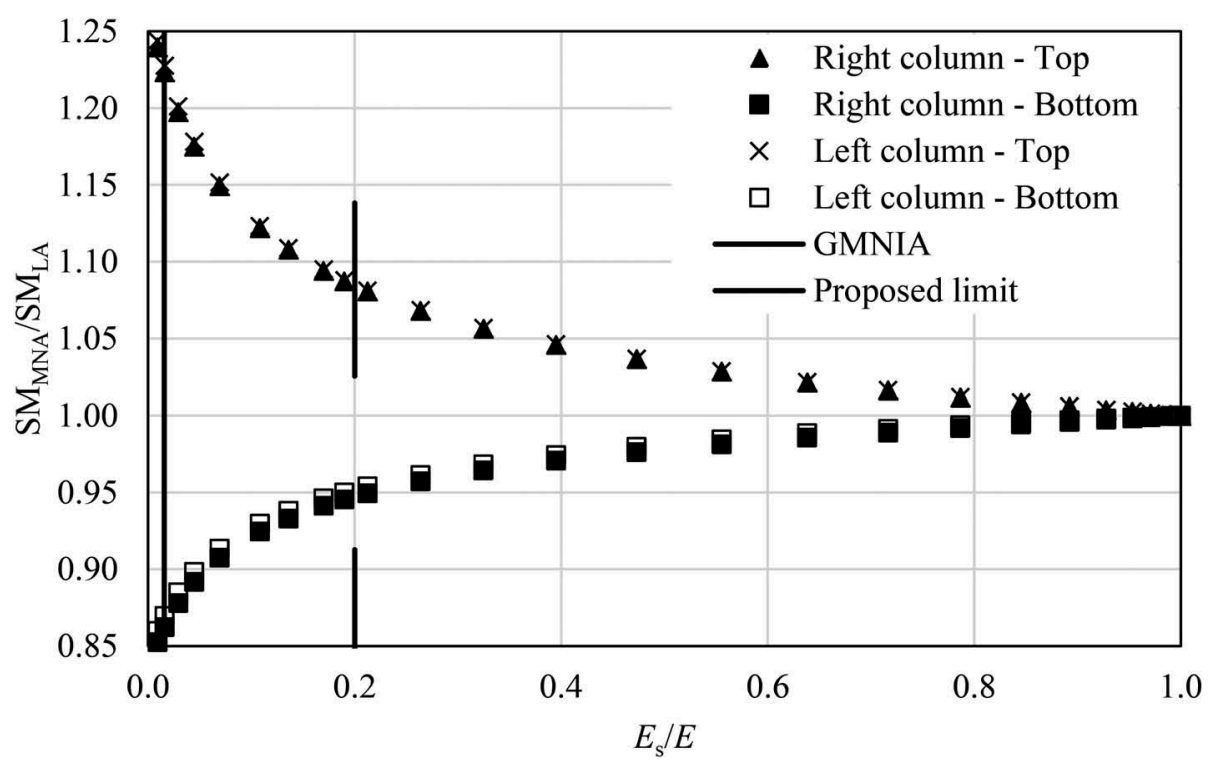

Figure 1. Ratio of internal moments from a plastic $\left(\mathrm{SM}_{\mathrm{MNA}}\right)$ and elastic $\left(\mathrm{SM}_{\mathrm{LA}}\right)$ analysis around the frame for an example $5 \times 10 \mathrm{~m}$ austenitic stainless steel portal frame plotted against the ratio of secant modulus $E_{\mathrm{s}}$ to elastic modulus $E$ at the most heavily stressed point in the frame.

$$
\begin{gathered}
\frac{E_{s}}{E}>0.2 \text { for elastic analysis } \\
E_{s}=\frac{E}{1+0.002 \frac{E}{\sigma}\left(\frac{\sigma}{f_{y}}\right)^{n}}
\end{gathered}
$$

Considering geometric nonlinearities at the frame level, EN 1993-1-1 (prEN 1993-1-1, 2020) and other international steel design standards state that second order effects may be neglected provided $\alpha_{\mathrm{cr}, \mathrm{sw}}$ is greater than or equal to 10 when an elastic analysis is employed, with $\alpha_{\mathrm{cr}, \mathrm{sw}}$ being the factor by which the design loading on a frame has to be increased to cause overall buckling in a global sway mode. The nonlinear stress-strain behaviour of stainless steel results in greater deformations as the material loses its stiffness and, therefore, a greater susceptibility to second order effects (Walport et al., 2019); a stricter requirement is therefore needed for plastic analysis. The influence of material nonlinearity on the sway stiffness of frames may be

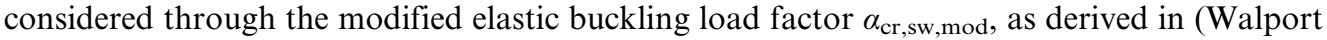
et al., 2019; Walport, Gardner \& Nethercot, 2019; Walport et al., 2021), and given by Equation 8 , where $K_{\mathrm{s}} / K$ is the ratio of the secant lateral stiffness of the frame $K_{\mathrm{s}}$ at the design value of the load to the initial lateral stiffness $K$ due to the influence of plasticity (i.e. as obtained from a first order plastic zone analysis) and $\mathrm{Y}$ is a factor that approximates the further loss of stiffness due to second order effects, taken from Table 1 (Walport et al., 2021).

$$
\alpha_{c r, s w, \bmod }=\frac{K_{s}}{K} Y \alpha_{c r, s w}
$$

The method provides a consistent treatment of second order effects between elastic and plastic global analysis i.e. a limit of 10 on both $\alpha_{\mathrm{cr}}$ and $\alpha_{\mathrm{cr} \text {,mod }}$, deeming second order effects sufficiently small to be ignored if the amplification of the internal forces is no more than $10 \%$ of the original internal forces determined according to first order theory. 


\begin{tabular}{lll}
\hline & $\begin{array}{l}\text { For single storey } \\
\text { portal frames }\end{array}$ & $\begin{array}{l}\text { For all } \\
\text { other frames }\end{array}$ \\
\hline Austenitic stainless steel & 0.80 & 0.55 \\
Duplex stainless steel & 0.85 & 0.60 \\
Ferritic stainless steel & 0.90 & 0.65 \\
\hline
\end{tabular}

\subsection{Design by inelastic analysis}

The most accurate representation of the behaviour of a structure is achieved through directly allowing for instability, plasticity, residual stresses and initial geometric imperfections through the use of second order (advanced) inelastic analysis with imperfections (i.e. GMNIA). The combined influence of residual stresses and geometric imperfections can be accounted for through the use of equivalent bow imperfections, as discussed in Section 3.2.1. Advanced analysis is commonly carried out using beam finite elements for ease of use and computational efficiency but these elements cannot capture local cross-section deformations. While shell finite elements are able to capture cross-section local buckling behaviour, they are computationally expensive. A practical solution is to use beam elements, with strain limits applied to simulate local buckling and control the level of plastic deformation and hence the capacity of the cross-section and ultimately the structure. In this approach (Fieber, Gardner \& Macorini, 2020, 2019; Walport, Gardner \& Nethercot, 2020a), the influence of material nonlinearity on the structural response is directly modelled through the definition of the full stress-strain curve of the material, while the strain limits, as defined by Equations (9) and (10), are taken from the continuous strength method (CSM), as further detailed in Section 3.2.2. Failure of the member/system is defined as the point at which either (1) the CSM strain limit is reached at any point in the system or (2) the peak load is attained during the analysis, whichever occurs first (Walport et al., 2019).

$$
\begin{gathered}
\frac{\varepsilon_{c s m}}{\varepsilon_{y}}=\frac{0.25}{\bar{\lambda}_{p}^{3.6}}+\frac{0.002}{\varepsilon_{y}} \quad \text { but } \leq \Omega \quad \text { for } \quad \bar{\lambda}_{p} \leq 0.68 \\
\frac{\varepsilon_{c s m}}{\varepsilon_{y}}=\left(1-\frac{0.222}{\bar{\lambda}_{p}^{1.05}}\right) \frac{1}{\bar{\lambda}_{p}^{1.05}}+\frac{0.002\left(\sigma / f_{y}\right)^{n}}{\varepsilon_{y}} \text { for } \quad 0.68<\bar{\lambda}_{p} \leq 1.0
\end{gathered}
$$

where $\bar{\lambda}_{p}=\sqrt{f_{y} / \sigma_{c r, c s}}$ is the local slenderness of the full cross-section, where $f_{\mathrm{y}}$ is the yield (or $0.2 \%$ proof) stress and $\sigma_{\text {cr,cs }}$ is the elastic local buckling stress of the full cross-section (Gardner, Fieber \& Macorini, 2019), $\varepsilon_{\mathrm{y}}$ is the yield strain, $\varepsilon_{\mathrm{u}}$ is the ultimate strain, $\sigma$ is the maximum compressive stress at the considered cross-section, $n$ is the strain hardening exponent and $\Omega$ is a project specific design parameter defining the permissible level of plastic deformation, with a recommended value of 15 to prevent excessive deformation (Fieber, Gardner \& Macorini, 2019).

The design approach enables consistent and accurate exploitation of cross-section slenderness dependent levels of spread of plasticity, moment redistribution and strain hardening. Additionally, the continuous nature of the approach allows all cross-sections (i.e. those of all cross-section classes) to be designed in the same way. Design by inelastic analysis with strain limits allows for safe and reliable assessment of structures while maintaining computational efficiency and practicality for widespread use in industry. 


\subsubsection{Equivalent bow imperfections}

Direct modelling of residual stresses in an analysis can present challenges to the designer and is not possible in many software packages; EN 1993-1-1 therefore provides 'equivalent' bow imperfections that implicitly account for the combined effects of geometric and material (i.e. residual stresses) imperfections. The equivalent bow imperfections given in prEN 1993-1-1 are for use with second order elastic analysis. These tabulated equivalent imperfections apply equally to second order elastic analysis of stainless steel members, provided the appropriate value of $\alpha$ is employed, though, due to the limiting slenderness in the stainless steel buckling curves not being a constant value, a revised equation, replacing the constant 0.2 with $\bar{\lambda}_{0}$, for back calculating the equivalent bow imperfection is needed, as given by Equation 11 (Walport, Gardner \& Nethercot, 2020b), where $\alpha$ is the imperfection factor, $\bar{\lambda}$ is the relative slenderness of the member, $\bar{\lambda}_{0}$ is the limiting relative slenderness and $M_{\mathrm{Rk}}$ and $N_{\mathrm{Rk}}$ are the characteristic value of the moment and axial resistance, respectively.

$$
e_{0}=\alpha\left(\bar{\lambda}-\bar{\lambda}_{0}\right) \frac{M_{R k}}{N_{R k}}
$$

It is generally not appropriate to use equivalent bow imperfections developed for elastic analysis in inelastic analyses, because the effects of plasticity can be double-counted and overpredictions (i.e. unconservative results) or under-predictions (i.e. conservative results) of buckling resistances can arise, depending on the form of the adopted material stress-strain curve (Walport, Gardner \& Nethercot, 2020b). For design by second order inelastic analysis, equivalent bow imperfection magnitudes may be calculated using Equation 12, where $L$ is the member length.

$$
\frac{e_{0}}{L}=\alpha \beta=\frac{\alpha}{150} \quad \text { but } \quad \frac{e_{0}}{L} \geq \frac{1}{1000}
$$

\subsubsection{The continuous strength method}

An elastic perfectly-plastic material model and the associated concept of cross-section classification underpin current metallic structural design codes. To overcome the shortcomings for application to materials that exhibit a high degree of nonlinearity and strain hardening, the continuous strength method was developed as a more rational alternative to cross-section classification (Gardner, 2008). The implications of the rounded stressstrain curve of stainless steel are that Class 4 cross-sections experience inelastic local buckling below the $0.2 \%$ proof stress while Class $1-3$ cross-sections can benefit from the substantial strain hardening exhibited by stainless steel beyond the $0.2 \%$ proof stress. Depending on the type and proportions of the structural element or system, the nonlinear material response can lead to either a reduced or enhanced capacity relative to an equivalent component featuring an elastic, perfectly plastic material response (Gardner, 2019; Walport, Gardner \& Nethercot, 2020b). In general, in strength governed scenarios, such as the in-plane bending resistance of stocky beams, the substantial strain hardening of stainless steel gives rise to capacity benefits, while in stability governed scenarios, the early onset of stiffness degradation results in reduced capacity.

The continuous strength method (CSM) is a deformation based design approach (Gardner, 2008; Gardner, Wang \& Liew, 2011; Afshan \& Gardner, 2013; Liew \& Gardner, 2015; Buchanan, Real \& Gardner, 2018; Zhao, Afshan \& Gardner, 2017) that enables a rational exploitation of the spread of plasticity, strain hardening and element interaction in the design of stainless steel cross-sections. The benefit of considering element interaction is greatest for cross-sections where the slenderness of the flange and web differ most, while the capacity increase from strain hardening is of most benefit for more compact cross-sections and for the materials exhibiting the highest level of hardening i.e. the austenitic grades. The strain limits also control the level of moment redistribution, the benefit of which depends on the 
proportions, loading and degree of indeterminacy in the structure. The magnitude of all these benefits will vary between structures but can be very significant and often up to $30 \%$.

\section{STABILITY DESIGN OF STAINLESS STEEL STRUCTURES IN AISC 370}

The new AISC 370 Specification (AISC, 2020) will encompass the design, fabrication and erection of hot-rolled and welded austenitic and duplex stainless steel structures. The provisions closely mirror AISC 360 (AISC, 2016), but deviate where necessary to account for the differences in material behaviour between stainless steel and carbon steel and the resulting influence on structural behaviour (Baddoo \& Francis, 2014; SCI, 2013). In AISC 370 (AISC, 2020), the influence of material nonlinearity and residual stresses can be accounted for in stability design by either (1) performing an elastic analysis but with reduced stiffness in the members or (2) performing an inelastic analysis. In the former case, the relative simplicity of elastic analysis is retained, while in the latter case, more accurate results are achieved.

\subsection{Second order elastic analysis with stiffness reduction}

Design by elastic analysis with stiffness reduction has been developed and widely used for carbon steel structures (Deierlein, 2003; Surovek-Maleck \& White, 2004a, 2004b). More recently, this method of design has been extended to the design of stainless steel structures (Walport, Kucukler \& Gardner, 2021) and is due to be incorporated into the upcoming AISC 370 (AISC, 2020) and ASCE-8 (ASCE, 2020) Specifications.

For design by second order elastic analysis, two stiffness reduction factors are defined: (1) $\tau_{\mathrm{b}}$, to account for the reduction in stiffness of members in compression due to the effects of yielding and residual stresses, and (2) $\tau_{\mathrm{g}}$, to account for the additional reduction in member stiffness due to combined compression plus bending. Additionally, for slender members, the $\tau_{\mathrm{g}}$ factor results in a system design strength equal to $\tau_{\mathrm{g}}$ times the elastic stability limit, which is equivalent to the margin of safety provided by the column buckling curves (Deierlein, 2003).

The proposed stiffness reduction factor $\tau_{\mathrm{b}}$ for stainless steel, accounting for the combined effects of material nonlinearity and residual stresses, was derived directly from the RambergOsgood expression, given by Equation 1. The stiffness reduction factor $\tau_{\mathrm{b}}$ was taken as the ratio of the tangent modulus $E_{\mathrm{t}}$ to the elastic modulus $E$, where $E_{\mathrm{t}}=d \sigma / d \varepsilon$ and $\sigma=P_{\mathrm{r}} / A$, where $P_{\mathrm{r}}$ is the axial compression and $A$ is the cross-sectional area. To allow for the influence of residual stresses, the strain hardening exponent $n$ was modified to an effective strain hardening exponent $n_{\text {eff }}$ through calibration against FE results for the tangent flexural stiffness obtained from a W8 $\times 31$ cross-section divided into 1440 monitoring areas, subjected to pure axial compression. The resulting stiffness reduction factor to account for the reduction in stiffness of stainless steel members in compression due to the effects of yielding and residual stresses is given by Equation 13, where $P_{\mathrm{r}}$ is the applied axial load, $P_{\mathrm{ns}}$ is the yield load and $f_{\mathrm{y}}$ is the yield stress, while the values of the effective strain hardening exponents $n_{\text {eff }}$ are presented in Table 2.

$$
\tau_{b}=\frac{1}{1+0.002 n_{e f f} \frac{E}{f_{y}}\left(\frac{P_{r}}{P_{n s}}\right)^{n_{e f f}-1}}
$$

Since $n_{\text {eff }}$ is a function of $n$, the varying degrees of roundedness of the stress-strain behaviour, as shown in Figure 2 for the typical grades of stainless steel (austenitic grade 301, duplex grade S32101 and ferritic grade 410S) is reflected in $\tau_{\mathrm{b}}$. The greatest reduction at low to moderate axial load levels occurs for austenitic stainless steel, mirroring the low limit of proportionality and the low value of the strain hardening exponent $n$.

Walport, Kucukler \& Gardner (2021), calibrated $\tau_{\mathrm{g}}$ against benchmark results from nonlinear finite element analysis of pin-ended stainless steel columns, beams and beam-columns, 
Table 2. Stiffness reduction factors $\tau$ for second order elastic analysis of stainless steel structures.

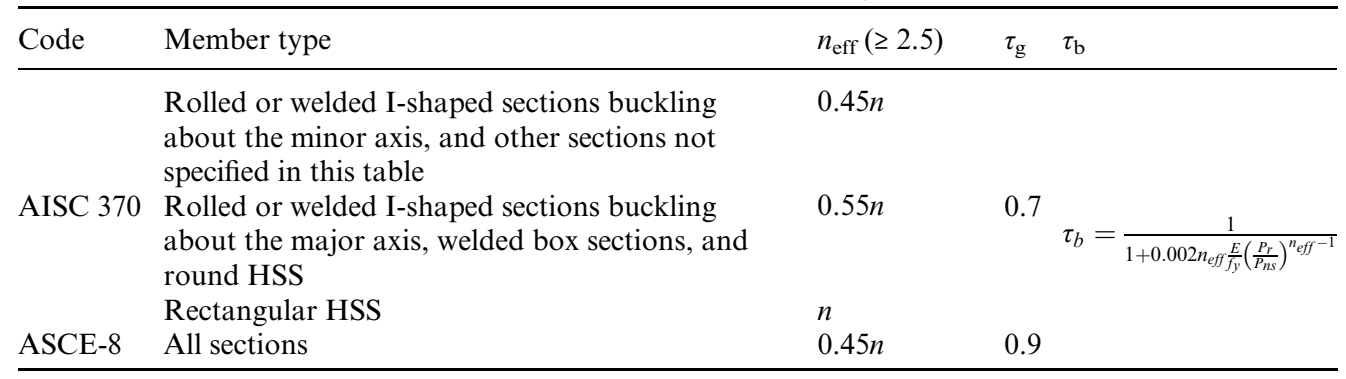

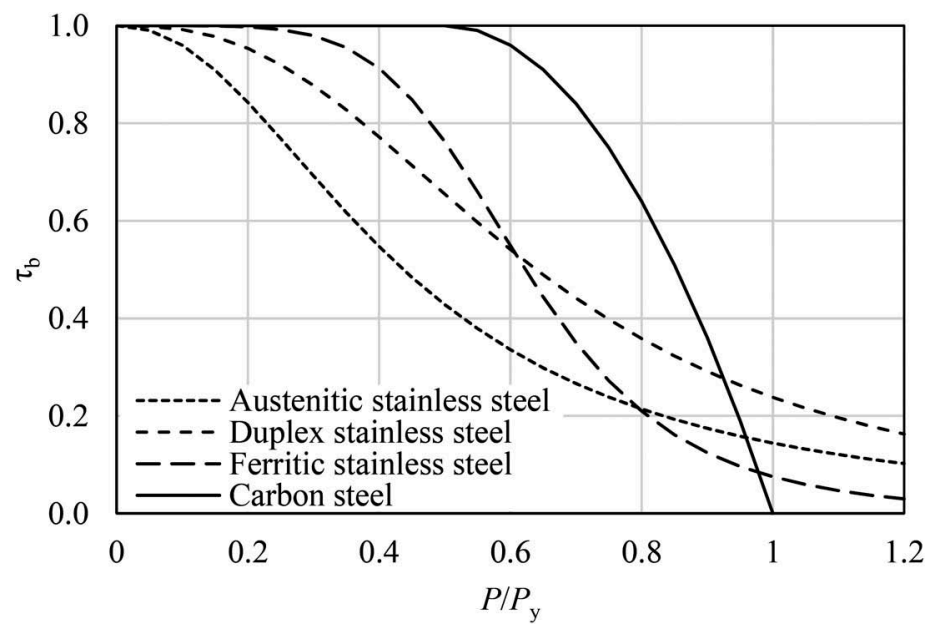

Figure 2. Stiffness reduction factor $\tau_{\mathrm{b}}$ for typical austenitic, duplex and ferritic grades of stainless steel for I-shaped sections buckling about the minor axis in AISC 370 and for all sections in ASCE-8.

as well as sample frames. For AISC 370 and ASCE-8, values of 0.7 and 0.9 are required to sufficiently account for the influence of plasticity, respectively. The difference between the proposed value of $\tau_{\mathrm{g}}$ for AISC 370 and ASCE- 8 reflects the different cross-section forcemoment interaction equation, the different column buckling curves and the different moment capacities between the two codes.

\subsection{Second order inelastic analysis}

As in prEN 1993-1-4, the most accurate representation of the behaviour of a structure is achieved through directly allowing for instability, plasticity, residual stresses and initial geometric imperfections through the use of second order (advanced) inelastic analysis with imperfections - see Section 3.2.

\section{PRACTICE}

With the growing need for sustainable and resilient structures, the use of high performance materials such as stainless steel, with its excellent durability characteristics, could help meet these future demands. Stainless steel has been used in construction since the 1920s; the earlier applications were predominantly chosen based on architectural appeal, for example in the cladding of the Chrysler Building in New York, while more contemporary applications take 
a)

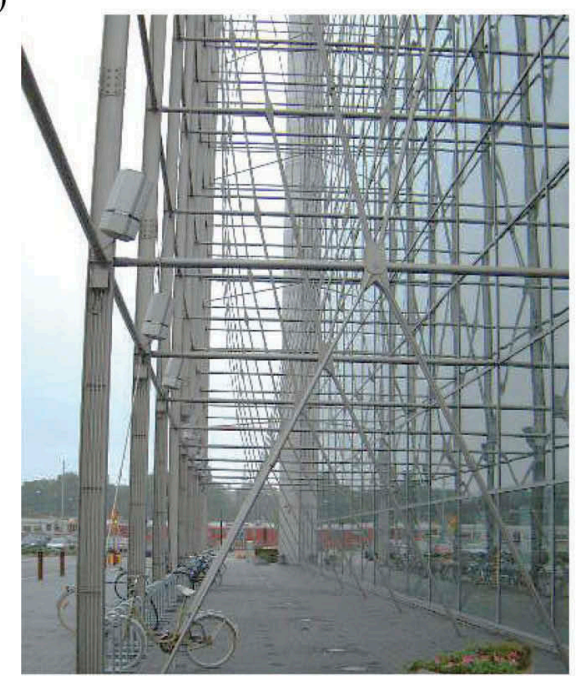

b)

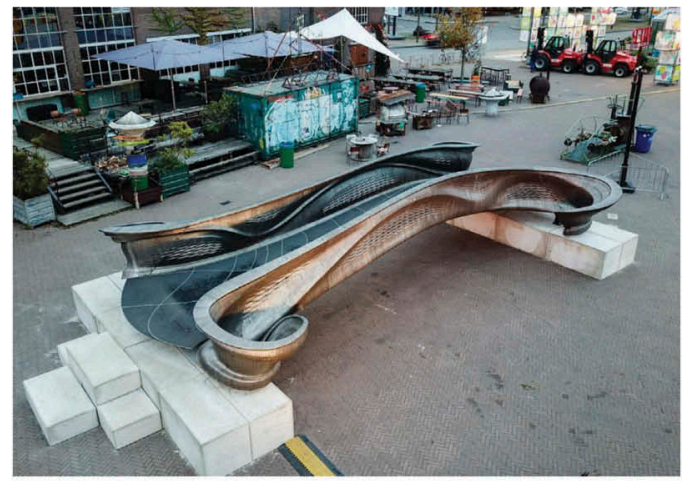

Figure 3. Recent examples of the use of structural stainless steel in practice. a) Sanomatalo Building, Helsinki; b) MX3D bridge at Dutch Design Week. 2018.

advantage of the desirable durability and structural properties, two examples of which are shown in Figure 3, including the Sanomatalo Building in Helsinki, in which stainless steel was used to form an exterior bracing system (Figure 3a).With a drive for more sustainable construction, the opportunities for the increased use of stainless steel is clear and this is reflected in the annual consumption of stainless steel increasing at a compound growth rate far in excess of other materials (Baddoo, 2008). Further information of the use of stainless steel in construction and more examples of practical structural applications may be found in (Baddoo, 2008; Gardner, 2005; SCI, 2020).

Another emerging innovation in construction is metal 3D printing, also known as additive manufacturing (Gardner, 2019; Buchanan \& Gardner, 2019). Additive manufacturing allows for highly optimised structures and engineered materials unlike those that can be achieved using traditional fabrication methods. Early research into the behaviour of metal 3D printed structural elements has been reported in (Kyvelou et al., 2020) (Buchanan et al., 2017), while a review of the methods, research, applications, opportunities and challenges for this technology has been presented in (Buchanan \& Gardner, 2019). Wire and arc additive manufacturing (WAAM) has been used to create the world's first metal 3D printed bridge constructed by the Dutch company MX3D, as shown in Figure 3b (Gardner et al., 2020). Additive manufacturing offers many opportunities for the construction sector, but there will also be fresh challenges and demands. The verification of the MX3D bridge has involved a significant amount of material, cross-section and structural testing, alongside advanced finite element simulations. This is a pioneering example of the potential of additive manufacturing and a offers a new way of thinking for the design and verification of such structures.

Embracing the digital age will be fundamental for increased sustainability within the structural engineering industry and this will rely on greater emphasis on the use of advanced analysis, as well as inspection and load testing. Structural design is significantly dictated by the current state of design guidance; the current sparsity of appropriate guidance on system-based design and advanced analysis is a barrier to its use in achieving optimal design. It is essential to ensure that working in the digital world is comparable to the traditional well-established and widely accepted approaches in terms of accessibility, flexibility, complexity and productivity. This requires the novel system-level advanced analysis approaches to be embedded in the design environment through clear guidance. International codes of practice and design guides 
form the core of that design guidance; inclusion of these new methods in the upcoming design codes presents a step-change for the future direction of structural design.

\section{CONCLUSIONS}

The nonlinear material stress-strain curve of stainless steel has a direct bearing on the structural response of stainless steel cross-sections, members and frames. With stainless steel being a high value material, its efficient use is paramount, and this is a particular incentive to embrace the opportunities offered by advanced system-level analysis and design. The most accurate representation of the behaviour of a structure is achieved by directly allowing for instability, plasticity, residual stresses and initial geometric imperfections in a second order inelastic analysis, but there is limited guidance to enable design on this basis in practice. As described in the present paper, the new provisions for design by advanced analysis in the upcoming second generation of the Eurocodes and the new American design standards will address this shortcoming, representing a huge opportunity for enabling more efficient and more widespread application of stainless steel in structural applications.

\section{REFERENCES}

Afshan, S. \& Gardner, L. (2013) Experimental study of cold-formed ferritic stainless steel hollow sections. Journal of Structural Engineering ASCE. 139 (5), 717-728.

AISC (2016) AISC 360. Specification for Structural Steel Buildings. AISC.

AISC (2020) AISC 370. Specification for Structural Stainless Steel Buildings. Draft. AISC.

Arrayago, I., Real, E. \& Gardner, L. (2015) Description of stress-strain curves for stainless steel alloys. Materials and Design. 87, 540-552.

ASCE (2020) ASCE-8-20: Specification for the Design of Cold-Formed Stainless Steel Structural Members. ASCE.

Baddoo, N. \& Francis, P. (2014) Development of design rules in the AISC Design Guide for structural stainless steel. Thin-Walled Structures. 83, 200-208.

Baddoo, N.R. (2008) Stainless steel in construction: A review of research, applications, challenges and opportunities. Journal of Constructional Steel Research. 64 (11), 1199-1206.

Buchanan, C. \& Gardner, L. (2019) Metal 3D printing in construction: A review of methods, research, applications, opportunities and challenges. Engineering Structures. 180, 332-348.

Buchanan, C., Matilainen, V.P., Salminen, A. \& Gardner, L. (2017) Structural performance of additive manufactured metallic material and cross-sections. Journal of Constructional Steel Research. 136, 35-48.

Buchanan, C., Real, E. \& Gardner, L. (2018) Testing, simulation and design of cold-formed stainless steel CHS columns. Thin-Walled Structures. 130 (May), 297-312.

Deierlein, G. (2003) Background and Illustrative Examples on Proposed Direct Analysis Method for Stability Design of Moment Frames. Report on behalf of AISC TC 10. 1-17.

EN 1993-1-2 (2005) Eurocode 3: Design of steel structures - Part 1-2: General rules - Structural fire design. CEN.

EN 1993-1-4:2006 + A1: (2015) Eurocode 3 - Design of steel structures - Part 1-4: General rules - Supplementary rules for stainless steels. Brussels, CEN.

Fieber, A., Gardner, L. \& Macorini, L. (2019) Design of structural steel members by advanced inelastic analysis with strain limits. Engineering Structures. 199, 109624.

Fieber, A., Gardner, L. \& Macorini, L. (2020) Structural steel design using second-order inelastic analysis with strain limits. Journal of Constructional Steel Research. 168, 105980.

Gardner, L. (2019) Stability and design of stainless steel structures - Review and outlook. Thin-Walled Structures. 141, 208-216.

Gardner, L. (2008) The continuous strength method. Proceedings of the Institution of Civil Engineers Structures and Buildings. 161 (3), 127-133.

Gardner, L. (2005) The use of stainless steel in structures. Progress in Structural Engineering and Materials. 7 (2), 45-55.

Gardner, L. \& Ashraf, M. (2006) Structural design for non-linear metallic materials. Engineering Structures. 28 (6), 926-934. 
Gardner, L., Fieber, A. \& Macorini, L. (2019) Formulae for calculating elastic local buckling stresses of full structural cross-sections. Structures. 17, 2-20.

Gardner, L., Insausti, A., Ng, K.T. \& Ashraf, M. (2010) Elevated temperature material properties of stainless steel alloys. Journal of Constructional Steel Research. 66 (5), 634-647.

Gardner, L., Kyvelou, P., Herbert, G. \& Buchanan, C. (2020) Testing and initial verification of the world's first metal 3D printed bridge. Journal of Constructional Steel Research. 172, 106233.

Gardner, L. \& Nethercot, D.A. (2004) Experiments on stainless steel hollow sections — Part 1: Material and cross-sectional behaviour. Journal of Constructional Steel Research. 60 (9), 1291-1318.

Gardner, L., Wang, F. \& Liew, A. (2011) Influence of strain hardening on the behavior and design of steel structures. International Journal of Structural Stability and Dynamics. 11 (5), 855-875.

Gardner, L. \& Yun, X. (2018) Description of stress-strain curves for cold-formed steels. Construction and Building Materials. 189, 527-538.

Hill, H.N. (1944) Determination of Stress-Strain Relations from 'Offset' Yield Strength Values. Technical Note No.927, National Advisory Committee for Aeronautics.

Kyvelou, P., Slack, H., Daskalaki Mountanou, D., Wadee, M.A., et al. (2020) Mechanical and microstructural testing of wire and arc additively manufactured sheet material. Materials and Design. 192, 108675.

Liang, Y., Manninen, T., Zhao, O., Walport, F., et al. (2019) Elevated temperature material properties of a new high-chromium austenitic stainless steel. Journal of Constructional Steel Research. $152,261-273$.

Liew, A. \& Gardner, L. (2015) Ultimate capacity of structural steel cross-sections under compression, bending and combined loading. Structures. 1, 2-11.

Mirambell, E. \& Real, E. (2000) On the calculation of deflections in structural stainless steel beams: an experimental and numerical investigation. Journal of Constructional Steel Research. 54 (1), 109-133.

prEN 1993-1-1 (2020) Eurocode 3 - Design of steel structures - Part 1-1: General rules and rules for buildings. CEN. Final Draft.

prEN 1993-1-14 (2019) Eurocode 3 - Design of steel structures - Part 1-14: Design by FE analysis. CEN. Draft 1.

prEN 1993-1-4 (2020) Eurocode 3 - Design of steel structures - Part 1-4: General rules - Supplementary rules for stainless steels. CEN. Draft 2.

Ramberg, W. \& Osgood, W. (1943) Description of stress-strain curves by three parameters. Technical Note No. 902, National Advisory Committee For Aeronautics. http://hdl.handle.net/2060/19930081614.

Rasmussen, K.J.R. (2003) Full-range stress-strain curves for stainless steel alloys. Journal of Constructional Steel Research. 59 (1), 47-61.

SCI (2017) Design Manual for Structural Stainless Steel Design. Fourth Edition. SCI Publication No. P413. UK, The Steel Construction Institute.

SCI (2020) prDG27. Draft 2.

SCI (2013) Structural Stainless Steel - AISC DG27. AISC. 159.

Surovek-Maleck, A.E. \& White, D.W. (2004a) Alternative Approaches for Elastic Analysis and Design of Steel Frames. I: Overview. Journal of Structural Engineering ASCE. 130 (8), 1186-1196.

Surovek-Maleck, A.E. \& White, D.W. (2004b) Alternative approaches for elastic analysis and design of steel frames. II: Verification studies. Journal of Structural Engineering ASCE. 130 (8), 1197-1205.

Theofanous, M., Saliba, N., Zhao, O. \& Gardner, L. (2014) Thin-Walled Structures Ultimate response of stainless steel continuous beams. Thin Walled Structures. 83, 115-127.

Walport, F., Arrayago, I., Gardner, L. \& Nethercot, D.A. (2021) Assessment and treatment of second order effects in plastically-design stainless steel frames. Journal of Constructional Steel Research. (In preparation).

Walport, F., Gardner, L. \& Nethercot, D.A. (2019) A method for the treatment of second order effects in plastically-designed steel frames. Engineering Structures. 200, 109516.

Walport, F., Gardner, L. \& Nethercot, D.A. (2020a) Design of structural stainless steel members by second order inelastic analysis with CSM strain limits. Thin-Walled Structures. in press, 107267.

Walport, F., Gardner, L. \& Nethercot, D.A. (2020b) Equivalent bow imperfections for use in design by second order inelastic analysis. Structures. 26, 670-685.

Walport, F., Gardner, L., Real, E., Arrayago, I., et al. (2019) Effects of material nonlinearity on the global analysis and stability of stainless steel frames. Journal of Constructional Steel Research. 152, 173-182.

Walport, F., Kucukler, M. \& Gardner, L. (2021) Stability design of stainless steel structures. Journal of Structural Engineering ASCE. Submitted for publication.

Zhao, O., Afshan, S. \& Gardner, L. (2017) Structural response and continuous strength method design of slender stainless steel cross-sections. Engineering Structures. 140, 14-25. 